\title{
Helicobacter pylori infection in Iran: demographic, endoscopic and pathological factors
}

\author{
Seyedeh Amineh Hojati ${ }^{1}$, Sara Kokabpeyk', Salma Yaghoubi', Farahnaz Joukar² ${ }^{2}$,
} Mehrnaz Asgharnezhad ${ }^{3}$ and Fariborz Mansour-Ghanaei ${ }^{4^{*}}$ (])

\begin{abstract}
Background: Helicobacter pylori (H. pylori) infection is the most important risk factor for gastritis and peptic ulcer. However, factors other than H. pylori are involved in its pathogenesis. In the current study, we aimed to compare the clinical manifestations and endoscopic and histopathological findings of patients with and without $H$. pylori infection.

Methods: In this cross-sectional study, 233 patients with dyspepsia, referred for endoscopy, were examined regarding the presence of $H$. pylori infection. During an endoscopic exam, 5 biopsy specimens were taken from the stomach. The criteria for the presence of $H$. pylori infection was the presence and identification of bacteria in pathology. Two groups of H. pylori-positive and H. pylori-negative patients were compared regarding their demographic, endoscopic, and pathological findings.

Results: Of 233 patients, 154 (66.1\%) were non-smokers, 201 (86.3\%) were not alcohol users, and 153 (65.7\%) used tap water. The most common symptom, reported in 157 (67.4\%) patients, was epigastric pain. There was a significant difference between patients with and without $H$. pylori infection in terms of the educational status, occupational status, family history of gastrointestinal cancer, and some gastrointestinal symptoms. Also, there was a significant relationship between the endoscopic and pathological findings of patients with H. pylori.

Conclusions: The results of the present study revealed that $H$. pylori infection was not associated with sex, alcohol consumption, or non-steroidal anti-inflammatory drug use. The role of $\mathrm{H}$. pylori in the pathophysiology of peptic ulcer was clarified. Also, there was a significant difference in the endoscopic and pathological findings of patients with $\mathrm{H}$. pylori.
\end{abstract}

Keywords: Helicobacter pylori, Endoscopy, Pathology

\section{Introduction}

Helicobacter pylori (H. pylori) is a gram-negative bacillus and one of the most common gastrointestinal pathogens globally [1]. Helicobacter pylori causes chronic gastritis,

\footnotetext{
*Correspondence: fmansourghanaei@gmail.com

${ }^{4}$ GI Cancer Screening and Prevention Research Center, Gastrointestinal and Liver Diseases Research Center and Caspian Digestive Diseases Research Center, Guilan University of Medical Sciences, Razi Hospital, Sardar-Jangle Ave, Rasht, Iran

Full list of author information is available at the end of the article
}

peptic ulcer, gastric marginal zone lymphoma of mucosaassociated lymphoid tissue (MALT lymphoma), and gastric carcinoma [2]. Recent investigations have reported that $H$. pylori infection is significantly associated with extra intestinal complications, such as iron-refractory iron deficiency anemia (IRIDA) [3], immune thrombocytopenic purpura [4], and vitamin B12 deficiency [5].

Helicobacter pylori infection occurs worldwide, although its exact incidence rate remains unknown. Besides, the prevalence of this infection varies by 
geographic region [1]. Many previous studies have indicated that the rate and risk of infection are significantly high in developing countries with a low socioeconomic status [6]. In this regard, a systematic review by Ghotaslou et al. [7] showed that about 4.4 billion people were infected with $H$. pylori worldwide. Northern America (37.1\%) and Australia (24.4\%) reported the lowest prevalence rates, while Africa (79.1\%), Latin America (63.4\%), and Asia (54.7\%) reported the highest incidence rates of infection [7].

Contaminated food and fecal-oral routes are the main routes of transmission; therefore, developments in hygiene practices are essential for reducing the rate of infection. Cats, cockroaches, rhesus monkeys, pig-tailed monkeys, and sheep are the main reservoir hosts for $H$. pylori [8]. Generally, patients with $H$. pylori infection are prone to gastric ulcer, gastric atrophy, intestinal metaplasia, and gastric carcinoma [9]. In 1994, this bacterium was recognized as the main carcinogen for gastric cancer [10]. Although the role of $H$. pylori in non-ulcer dyspepsia is unclear, the rate of infection is high in these patients.

The genetic predisposition of the host is very important in H. pylori infection [11]. According to previous studies, more than $90 \%$ of duodenal ulcers and $60 \%$ of gastric ulcers are associated with $H$. pylori infection [12]; however, this association is not entirely known yet. Some studies suggest that the prevalence of $H$. pylori is much higher than peptic ulcer. Therefore, the question arises as to why not all patients with $H$. pylori infection have peptic ulcer disease. On the other hand, many patients with peptic ulcers are negative for $H$. pylori infection. In this regard, Chu et al. examined patients with peptic ulcers from 1996 to 2002, and the results showed that 30\% of the patients were negative for $\mathrm{H}$. pylori. Also, in a study by Wei et al. in 2014, $62.3 \%$ of the patients were negative for H. pylori [13].

Poor health standards, cultural background, diet, oral hygiene, large families, consumption of unhealthy water or contaminated vegetables, and swimming in a river are the main risk factors for $H$. pylori infection [14]. There are several methods for the rapid and accurate diagnosis of $H$. pylori infection. These methods can be divided into two categories of endoscopic and non-endoscopic. Nonendoscopic procedures include histology, rapid urease testing, culture, serology, urea breath test, and molecular techniques [15].

Guilan Province is one of the rainy provinces in north of Iran, which lies along the Caspian Sea. Considering the important role of $H$. pylori in peptic ulcer and other gastrointestinal disorders, besides the possible role of other factors, it is necessary to compare patients with positive and negative results for $H$. pylori. Also, no study has been carried out on the difference in the demographic, endoscopic, and pathological data of patients with and without $H$. pylori infection in Guilan Province in north of Iran. Therefore, this study aimed to assess the above mentioned factors in patients with and without $H$. pylori infection.

\section{Materials and methods \\ Patients}

From June 2017 to August 2019, in coordination with the endoscopy department of Caspian Gastroenterology and Liver Clinic, patients with dyspepsia, referred for endoscopy, were examined for $H$. pylori infection. Diagnosis of H. pylori infection was established for all patients using pathology and rapid urease test (RUT). Patients were then divided into two groups of $H$. pylori-positive and $H$. pylori-negative. The two groups were compared in terms of their demographic information and their endoscopic and pathological findings. All patients, aged above 12 years, who were referred to the endoscopy department of Caspian Gastroenterology and Liver Clinic, were included in this study. The exclusion criteria were pregnancy, use of an acid inhibitor, and use of anti-H. pylori drugs.

\section{Data collection}

For data collection, a questionnaire was used in this study, which included the subject's first name, last name, age, sex, body mass index (BMI), level of education, number of family members, smoking status, alcohol consumption, occupation, marital status, source of drinking water, $H$. pylori infection, family history of cancer, and gastrointestinal symptoms. The questionnaire was delivered to all patients and completed by the patient or the patient's companion.

\section{Specimens}

Following local lidocaine $10 \%$ sedation, upper gastrointestinal endoscopy was performed via video endoscopy (GIF type V, Olympus Optical Co., Ltd., Tokyo, Japan); an endoscopist reported the results. Biopsy specimens were collected from five different regions of the stomach. Also, for histological examinations, four specimens were taken (one from the fundus, one from the body, and two from the antrum). Moreover, RUT was used for the diagnosis of $H$. pylori infection in a specimen from the antrum.

All specimens were placed in a separate bottle, containing formalin $10 \%$ and sent to the pathology laboratory. Various premalignant lesions, including intestinal metaplasia (grade I to III), atrophic gastritis, dysplasia, and $H$. pylori infection, were found after fixation, staining, and microscopic examination; they were then classified based on the Sydney criteria $[16,17]$. It should be noted that the 
pathologist was blinded to the patients' data, diagnostic index, and endoscopic findings.

\section{Data analysis}

Data were analyzed using chi square test and logistic regression (univariate and multivariate). Results were expressed as crude and adjusted odds ratios (ORs) with 95\% confidence intervals (CIs). All statistical analyses were conducted using the statistics program in SPSS version 21 (SPSS Inc., Chicago, IL, USA). Graphs were also drawn using Prism 7. $P$ values less than 0.05 were considered statistically significant.

\section{Results}

The patients' demographic information is presented in Table 1 . The most commonly reported gastrointestinal symptom was epigastric pain, reported in 157 (67.4\%) patients. There was a significant difference between patients with and without $H$. pylori infection in terms of the educational status, occupational status, family history of gastrointestinal cancer, and some gastrointestinal symptoms $(P<0.001)$ (Table 2$)$.

The pathology report indicated that 109 (46.8\%) and 124 (53.2\%) patients were positive and negative for $H$. pylori, respectively. The results also showed a significant difference between the two groups in terms of mucosal erosions in the stomach and duodenum, as well as normal endoscopic findings $(P=0.001)$ (Table 3$)$.

The frequency of the patients' pathological findings is shown in Table 4. The results showed a significant difference between the two groups regarding normal gastric glands and intestinal metaplasia $(P=0.001)$.

\section{Discussion}

In this study, 233 patients with gastrointestinal diseases were first examined for $H$. pylori infection, and then, they were divided into $H$. pylori-positive and $H$. pylorinegative groups. Analysis of demographic data showed that the rate of $H$. pylori infection was significantly higher in married people, patients with more than three family members, and patients with a history of cancer. Also, the incidence of gastrointestinal symptoms, including epigastric pain, weight loss, and loss of appetite, was significantly higher in $H$. pylori-positive patients as compared to $H$. pylori-negative patients.

Various studies have suggested that factors, such as age, congestion, high number of family members, and poor health, especially in childhood, are the main causes of infection with $H$. pylori [18-20]. Age is one of the most important factors in the development of $H$. pylori infection. Many recent studies have indicated a significant association between this factor and the incidence of $H$. pylori infection [21]. In a study by Rowland
Table 1 The results of demographic and clinical information of patients

\begin{tabular}{|c|c|}
\hline Demographic and clinical data & Frequency (\%) \\
\hline \multicolumn{2}{|l|}{ Sex } \\
\hline Men & $125(53.6)$ \\
\hline Women & $108(46.4)$ \\
\hline \multicolumn{2}{|l|}{ Age } \\
\hline$<35$ & $57(24.5)$ \\
\hline $35-45$ & $42(18.0)$ \\
\hline$>45$ & $134(57.5)$ \\
\hline \multicolumn{2}{|l|}{ BMI } \\
\hline$<18.5$ & $3(1.3)$ \\
\hline $18.5-24.9$ & $35(15.0)$ \\
\hline $25-29.9$ & $145(62.2)$ \\
\hline$>30$ & $50(21.5)$ \\
\hline \multicolumn{2}{|l|}{ Number of family members } \\
\hline$<3$ & $93(39.9)$ \\
\hline$\geqq 3$ & $140(60.1)$ \\
\hline \multicolumn{2}{|l|}{ Smoking } \\
\hline Yes & $79(33.9)$ \\
\hline No & $154(66.1)$ \\
\hline \multicolumn{2}{|l|}{ Drink alcohol } \\
\hline Yes & $32(13.7)$ \\
\hline No & $201(86.3)$ \\
\hline \multicolumn{2}{|l|}{ Education } \\
\hline Illiterate & $10(4.3)$ \\
\hline Under diploma & $47(20.2)$ \\
\hline Diploma & $83(35.6)$ \\
\hline Upper graduated & $93(39.9)$ \\
\hline \multicolumn{2}{|l|}{ Marital status } \\
\hline Single & $44(18.9)$ \\
\hline Married & $186(79.8)$ \\
\hline Divorces & $3(1.3)$ \\
\hline \multicolumn{2}{|l|}{ Occupation } \\
\hline Unemployed & $56(24.0)$ \\
\hline Housekeeping & $71(30.5)$ \\
\hline Employee & $39(16.7)$ \\
\hline Self employed & $67(28.8)$ \\
\hline \multicolumn{2}{|l|}{ Source of drinking water } \\
\hline River & $1(0.4)$ \\
\hline Tap & $153(65.7)$ \\
\hline Mineral & $48(20.6)$ \\
\hline Tap and Mineral & $31(13.3)$ \\
\hline \multicolumn{2}{|l|}{ Family history of cancer } \\
\hline Yes & $44(18.9)$ \\
\hline No & 189 (81.9) \\
\hline \multicolumn{2}{|l|}{ Gastrointestinal sign and symptoms } \\
\hline Epigastric pain & $157(67.4)$ \\
\hline Heartburn & $107(45.9)$ \\
\hline Reflux & $76(32.6)$ \\
\hline Weight loss & $55(23.6)$ \\
\hline Decreased appetite & $64(27.5)$ \\
\hline Early satiety & $17(7.3)$ \\
\hline The presence of blood in the stool & $9(3.9)$ \\
\hline Iron deficiency anemia & $27(11.6)$ \\
\hline
\end{tabular}

$B M I$ body mass index 
et al. [19], young children before the age of 3 years were at risk of $H$. pylori infection, whereas the risk of infection was very low after 5 years of age. In the present study, most people $(59.5 \%)$ with $H$. pylori were in the age group of 35-45 years [19]. Similar to our findings, Toyoshima et al. [22] reported that patients in the age range of 40-59 years had significantly higher serum antibody titers for $H$. pylori as compared to other age groups.

In the present study, the incidence of $H$. pylori infection was not significantly different between males and females. The results of multiple studies are consistent with our findings, which showed that $H$. pylori infection is not sex-dependent [23].

While smoking consumption is well-known risk factors for the incidence of $H$. pylori infection, no significant difference was observed in the present study. Our results are similar to previous studies [24-27].

Also, the number of family members is one of the factors evaluated in the present study; however, no significant relationship was found between this factor and the incidence of $H$. pylori infection. On the other hand, many studies have reported inconsistent results. It is hypothesized that with an increase in the number of family members, the amount of contact with the outside environment increases, contact between people increases indoors, and therefore, the incidence of infection may increase [28].

Education is one of the factors that is inversely related to the incidence of $H$. pylori infection; in other words, people with higher education are less likely to have this type of disease [29]. Several previous studies have found the relation between lower education and a high prevalence of $H$. pylori [30-35]. However, this study showed that the infection rate of $H$. pylori among illiterate individuals was significantly lower than that in literate participants. $A$ small sample size can also lead to this result.

In our study, unemployed participants were found to be infected with $H$. pylori more often than other participants. Several studies have analyzed and confirmed the relationship between socioeconomic status and frequency of $H$. pylori infection. [36, 37]. However, we were not able to confirm this, because in our study, the income of the participants was not clear.

Based on the present results, gastric and duodenal mucosal erosions were significantly more common in $H$. pylori-positive patients as compared to $H$. pylori-negative patients. Similar to our findings, a study by Lehmann et al. [38] showed that the rate of H. pylori infection in patients with gastric erosion was significantly higher than those negative for $H$. pylori $(P<0.01)$. Overall, gastric mucosal erosive changes may be acute or chronic. Erosive changes seem to be common in patients with peptic ulcer and hyperacidity and may be a manifestation of $H$. pyloriinduced peptic ulcer in many patients. Notwithstanding,
H. pylori is considered to be the primary cause of most types of gastritis, although its role as a causative agent in gastric erosions is unclear [39].

In this study, endoscopy showed that there was no difference between $H$. pylori-negative and $H$. pylori-positive in terms of gastric and duodenal ulcers. Previous study has revealed that more than $90 \%$ of duodenal ulcers and $60 \%$ of gastric ulcers are associated with $H$. pylori infection [40]. On the other hand, the incidence of peptic ulcer and gastritis is increasing in patients who are susceptible to $H$. pylori [41, 42]. However, the results of some studies are inconsistent with these findings [13, 42-44].

Comparison of pathological findings in patients with and without $H$. pylori infection showed that neutrophil infiltration was the most common finding, observed in 124 (53.2\%) patients [45]. The results of this study revealed that the incidence and severity of neutrophil infiltration in to the mucosal layer and muscularis propria, normal gastric glands, complete intestinal metaplasia, and incomplete intestinal metaplasia were significantly higher in $\mathrm{H}$. pylori-positive patients. In the current study, $75.8 \%$ of patients with $H$. pylori showed signs of neutrophil infiltration in the mucosal layer and muscularis propria. Besides, incomplete intestinal metaplasia and complete intestinal metaplasia were reported in $100 \%$ and $96.4 \%$ of cases, respectively. Intestinal metaplasia is characterized by the loss of mucus-secreting capillaries and their replacement by goblet cells in the epithelium, which manifests in three forms; the third form is known as incomplete intestinal metaplasia.

In a similar study, Fontham et al. [46] indicated that $87 \%$ of patients with gastric cancer had intestinal metaplasia, and significant differences were found with normal controls. Moreover, Silva et al. [47] reported the highest incidence of $H$. pylori in areas with incomplete intestinal metaplasia; this type of metaplasia indicates long-term damage to the mucosa and leads to cancer. There are different reports on the prevalence of $H$. pylori infection in chronic gastritis and intestinal metaplasia, and many studies have attempted to find the link between direct or indirect effects of $H$. pylori and histological findings, especially dysplasia and gastric cancer.

In the present study on patients with and without $H$. pylori infection, gastric atrophy was reported in $52.4 \%$ and $47.6 \%$ of patients, respectively; this difference was not statistically significant. In a similar study, Nordenstedt et al. [48] reported that $41.5 \%$ of patients with $H$. pylori-negative gastritis had atrophy. Overall, gastric mucosal atrophy is the endpoint of chronic processes, such as chronic gastritis associated with $H$. pylori infection, other unidentified environmental factors, and autoimmunity directed against gastric glandular cells [49]. Atrophic gastritis is mostly caused by $H$. pylori infection. 
Table 2 Univariate and multivariate logistic regression analysis of factors associated with $\mathrm{H}$. pylori positive and negative

\begin{tabular}{|c|c|c|c|c|c|c|c|}
\hline Demographic and clinical data & $\begin{array}{l}\text { Total } \\
\mathrm{N}=233 \\
\mathrm{n}(\%)\end{array}$ & $\begin{array}{l}\text { H. pylori } \\
\text { positive } \\
\mathrm{N}=109 \\
\mathrm{n}(\%)\end{array}$ & $\begin{array}{l}H . \text { pylori } \\
\text { negative } \\
N=124 \\
n(\%)\end{array}$ & OR crude $(95 \% \mathrm{Cl})$ & $P$ Value & OR adjusted $(95 \% \mathrm{Cl})$ & $P$ value \\
\hline \multicolumn{8}{|l|}{ Gender } \\
\hline Men & $125(53.6)$ & $55(44.0)$ & $70(56.0)$ & $0.78(0.46-1.31)$ & 0.430 & $0.51(0.20-1.33)$ & 0.174 \\
\hline Women & $108(46.4)$ & $54(50.0)$ & $54(50.0)$ & Ref & & Ref & \\
\hline \multicolumn{8}{|l|}{ Age group } \\
\hline$<35$ & $57(24.5)$ & $21(36.8)$ & $36(63.2)$ & $1.25(0.80-2.87)$ & 0.196 & $0.72(0.20-2.54)$ & 0.612 \\
\hline $35-45$ & $42(18.0)$ & $25(59.5)$ & $17(40.5)$ & $0.60(0.29-1.21)$ & 0.159 & $2.47(0.81-7.53)$ & 0.111 \\
\hline$>45$ & $134(57.5)$ & $63(47.0)$ & $71(53.0)$ & Ref & - & Ref & - \\
\hline \multicolumn{8}{|l|}{ BMl } \\
\hline$<18.5$ & $3(1.3)$ & $0(0.0)$ & $3(100.0)$ & N/A & - & N/A & - \\
\hline $18.5-24.9$ & $35(15.0)$ & $17(48.6)$ & $18(51.4)$ & $1.52(0.57-4.07)$ & 0.398 & $1.76(0.44-7.00)$ & 0.420 \\
\hline $25-29.9$ & $145(62.2)$ & $69(47.6)$ & $76(52.4)$ & $1.32(0.57-3.04)$ & 0.504 & $1.82(0.61-5.35)$ & 0.277 \\
\hline$>30$ & $50(21.5)$ & $23(46.0)$ & $27(54.0)$ & Ref & - & Ref & - \\
\hline \multicolumn{8}{|l|}{ Number of family member } \\
\hline$<3$ & 93 (39.9) & $37(39.8)$ & $56(60.2)$ & $0.62(0.36-1.06)$ & 0.084 & $0.74(0.35-1.56)$ & 0.428 \\
\hline$>3$ & $140(60.1)$ & $72(51.4)$ & 68 (48.6) & Ref & & Ref & - \\
\hline \multicolumn{8}{|l|}{ Smoking } \\
\hline Yes & 79 (33.9) & $33(41.8)$ & $46(58.2)$ & $0.73(0.42-1.27)$ & 0.332 & $0.68(0.29-1.62)$ & 0.395 \\
\hline No & $154(66.1)$ & $76(49.4)$ & $78(50.6)$ & Ref & & Ref & - \\
\hline \multicolumn{8}{|l|}{ Alcohol drink } \\
\hline Yes & $32(13.7)$ & $16(50.0)$ & $16(50.0)$ & $1.16(0.55-2.45)$ & 0.707 & $1.75(0.60-5.08)$ & 0.301 \\
\hline No & $201(86.3)$ & $93(46.3)$ & $108(53.7)$ & Ref & & Ref & - \\
\hline \multicolumn{8}{|l|}{ Education } \\
\hline Illiterate & $10(4.3)$ & $3(30.0)$ & $7(70.0)$ & $0.45(0.11-1.87)$ & 0.277 & $0.13(0.02-0.84)$ & 0.033 \\
\hline Under diploma & $47(20.2)$ & $24(51.1)$ & $23(48.9)$ & $1.11(0.55-2.24)$ & 0.765 & $0.43(0.12-1.58)$ & 0.209 \\
\hline Diploma & $83(35.6)$ & $37(44.6)$ & $46(55.4)$ & $0.85(0.47-1.55)$ & 0.613 & $0.47(0.17-1.28)$ & 0.141 \\
\hline Upper graduated & $93(39.9)$ & $45(48.4)$ & $48(51.6)$ & Ref & - & Ref & - \\
\hline \multicolumn{8}{|l|}{ Marital status } \\
\hline Single & 44 (18.9) & $12(27.3)$ & $32(72.7)$ & $0.35(0.17-0.73)$ & 0.01 & $0.38(0.12-1.13)$ & 0.082 \\
\hline Married & $189(81.1)$ & $97(51.1)$ & $92(48.9)$ & Ref & & Ref & - \\
\hline \multicolumn{8}{|l|}{ Occupation } \\
\hline Unemployed & $56(24.0)$ & $32(57.1)$ & $24(42.9)$ & $2.24(1.08-4.62)$ & 0.029 & $6.70(2.22-20.23)$ & 0.001 \\
\hline Housekeeping & $71(30.5)$ & $32(45.1)$ & $39(54.9)$ & $1.37(0.69-2.72)$ & 0.356 & $1.03(0.30-3.49)$ & 0.951 \\
\hline Employee & $39(16.7)$ & $20(51.3)$ & $19(48.7)$ & $1.76(0.79-3.93)$ & 0.162 & $0.90(0.28-2.80)$ & 0.856 \\
\hline Self employed & $67(28.8)$ & $25(37.3)$ & $42(62.7)$ & Ref & - & Ref & - \\
\hline \multicolumn{8}{|l|}{ Drinking water source } \\
\hline River & $1(0.4)$ & $1(100.0)$ & $0(0.0)$ & N/A & - & N/A & - \\
\hline Tap & $153(65.7)$ & $68(44.4)$ & 85 (55.6) & $0.85(0.39-1.84)$ & 0.688 & $0.97(0.36-2.57)$ & 0.957 \\
\hline Mineral & $48(20.6)$ & $25(52.1)$ & $23(47.9)$ & $1.15(0.47-2.86)$ & 0.748 & $1.07(0.33-3.46)$ & 0.909 \\
\hline Tap and Mineral & $31(13.3)$ & $15(48.4)$ & $16(51.6)$ & Ref & - & Ref & - \\
\hline \multicolumn{8}{|c|}{ Family history of gastrointestinal cancer } \\
\hline Yes & $44(18.9)$ & $30(68.2)$ & $14(31.8)$ & $2.98(1.48-5.99)$ & 0.002 & $3.52(1.48-8.35)$ & 0.004 \\
\hline No & $189(81.9)$ & $79(41.8)$ & $110(58.2)$ & Ref & & Ref & - \\
\hline \multicolumn{8}{|l|}{ Gastrointestinal sign and symptoms ${ }^{\mathrm{a}}$} \\
\hline Epigastric pain & $157(67.4)$ & $85(54.1)$ & $72(45.9)$ & $2.70(1.50-4.83)$ & 0.001 & $4.67(1.92-11.34)$ & 0.001 \\
\hline Heartburn & $107(45.9)$ & $24(31.6)$ & $52(68.4)$ & $1.06(0.63-1.78)$ & 0.895 & $1.83(0.89-3.75)$ & 0.009 \\
\hline Reflux & $76(32.6)$ & $34(44.7)$ & $42(55.3)$ & $0.88(0.51-1.53)$ & 0.677 & $1.35(0.61-2.99)$ & 0.458 \\
\hline Weight loss & $55(23.6)$ & $34(61.8)$ & $21(38.2)$ & $2.22(1.19-4.13)$ & 0.013 & $3.38(1.34-8.49)$ & 0.009 \\
\hline
\end{tabular}


Table 2 (continued)

\begin{tabular}{|c|c|c|c|c|c|c|c|}
\hline Demographic and clinical data & $\begin{array}{l}\text { Total } \\
\mathrm{N}=233 \\
\mathrm{n}(\%)\end{array}$ & $\begin{array}{l}\text { H. pylori } \\
\text { positive } \\
\mathrm{N}=109 \\
\mathrm{n}(\%)\end{array}$ & $\begin{array}{l}\text { H. pylori } \\
\text { negative } \\
\mathrm{N}=124 \\
\mathrm{n}(\%)\end{array}$ & OR crude $(95 \% \mathrm{Cl})$ & $P$ Value & OR adjusted $(95 \% \mathrm{Cl})$ & $P$ value \\
\hline Decreased appetite & $64(27.5)$ & $35(54.7)$ & $29(45.3)$ & $1.54(0.86-2.76)$ & 0.144 & $1.62(0.69-3.78)$ & 0.262 \\
\hline Early satiety & $17(7.3)$ & $8(47.1)$ & $9(52.9)$ & $1.01(0.37-2.72)$ & 0.981 & $1.73(0.44-6.77)$ & 0.425 \\
\hline The presence of blood in the stool & $9(3.9)$ & $2(22.2)$ & $7(77.8)$ & $0.31(0.06-1.55)$ & 0.181 & $0.66(0.11-3.88)$ & 0.654 \\
\hline Iron deficiency anemia & $27(11.6)$ & $15(55.6)$ & $12(44.4)$ & $1.48(0.66-3.33)$ & 0.413 & $1.62(0.55-4.79)$ & 0.378 \\
\hline
\end{tabular}

$P$ values less than 0.05 were considered statistically significant

H. pylori Helicobacter pylori, $\mathrm{BMI}$ body mass index, OR odd ratio, $\mathrm{Cl}$ confidence interval

a \%s may not add up to 100 as one patient be diagnosed with more than one Gastrointestinal sign and symptoms

Table 3 Comparison of endoscopic findings by participants with positive and negative H. pylori

\begin{tabular}{|c|c|c|c|c|}
\hline Endoscopic findings & $\begin{array}{l}\text { Total } \\
\mathrm{N}=233 \\
\mathrm{n}(\%)\end{array}$ & $\begin{array}{l}\text { H. pylori positive } \mathrm{N}=109 \\
\mathrm{n}(\%)^{\mathrm{a}}\end{array}$ & $\begin{array}{l}\text { H. pylori negative } \mathrm{N}=124 \\
\mathrm{n}(\%)\end{array}$ & $P$ value \\
\hline Gastric ulcer & $18(7.7)$ & $8(44.4)$ & $10(55.6)$ & 0.5 \\
\hline Duodenal ulcer & $6(2.5)$ & $1(16.7)$ & $5(83.3)$ & 0.1 \\
\hline Mucosal erosions in the stomach & $98(42.0)$ & $71(42.4)$ & $27(27.6)$ & 0.001 \\
\hline Mucosal erosions in the duodenum & $68(29.1)$ & $55(80.9)$ & $13(19.1)$ & 0.001 \\
\hline Antral nodularity & $13(5.5)$ & $3(23.1)$ & $10(76.9)$ & 0.06 \\
\hline Body nodularity & $20(8.5)$ & $13(65.0)$ & $7(35.0)$ & 0.07 \\
\hline Duodenal nodularity & $2(0.01)$ & $1(50.0)$ & $1(50.0)$ & 0.7 \\
\hline Normal & $94(40.3)$ & 25 (26.6) & $69(73.4)$ & 0.001 \\
\hline
\end{tabular}

$P$ values less than 0.05 were considered statistically significant

Table shows the various endoscopy findings. Ninety four patients (40.3\%) had normal endoscopy results. Significantly more patients with H. pylori positive had mucosal erosions in the stomach, and duodenum

H. pylori Helicobacter pylori

a $\%$ s may not add up to 100 as one patient be diagnosed with more than one endoscopic finding

Table 4 Comparison of pathological findings by participants with H. pylori positive and negative

\begin{tabular}{|c|c|c|c|c|}
\hline Pathological findings & $\begin{array}{l}\text { Total } \\
\mathrm{N}=233 \\
\mathrm{n}(\%)\end{array}$ & $\begin{array}{l}\text { H. pylori positive } \mathrm{N}=109 \\
\mathrm{n}(\%)^{\mathrm{a}}\end{array}$ & $\begin{array}{l}\text { H. pylori negative } \mathrm{N}=124 \\
\mathrm{n}(\%)\end{array}$ & $P$ value \\
\hline Neutrophil infiltration & $124(53.2)$ & $94(75.8)$ & $30(24.2)$ & 0.001 \\
\hline Abscess + mucin decrease & $1(0.04)$ & $1(100.0)$ & $0(0.0)$ & 0.4 \\
\hline Normal gastric glands & $80(34.3)$ & $2(2.5)$ & $78(98.5)$ & 0.001 \\
\hline Complete intestinal metaplasia & $12(5.1)$ & $12(100.0)$ & $0(0.0)$ & 0.001 \\
\hline Incomplete intestinal metaplasia & $28(12.1)$ & $27(96.4)$ & $1(3.6)$ & 0.001 \\
\hline Atrophy & $84(36.0)$ & $44(52.4)$ & $40(47.6)$ & 0.1 \\
\hline High grade dysplasia & $1(0.04)$ & $1(100.0)$ & $0(0.0)$ & 0.4 \\
\hline
\end{tabular}

$P$ values less than 0.05 were considered statistically significant

Table shows the various pathologic findings. Significantly more patients with $H$. pylori positive had neutrophil infiltration, complete intestinal metaplasia, and incomplete intestinal metaplasia compared with patients without H. pylori

H. pylori Helicobacter pylori

a \%s may not add up to 100 as one patient be diagnosed with more than one Pathological finding

Therefore, some people classified as $H$. pylori-negative were previously infected with this bacterium. However, we cannot determine whether atrophic gastritis resulted from $H$. pylori infection or autoimmunity. It may be associated with long-term $H$. pylori infection and an 
autoimmune process that progressively destroys the oxyntic mucosa [50].

\section{Limitation}

This study has some limitations. The sample undertaken in a single medical center, Guilan Gastroenterology and Liver Clinic, which may not be a general representation of Iran although the patients came from a variety of socioeconomic backgrounds. In addition, the sample size was small for assessing some risk factors. Another limitation of this study is that we lacked information on personal income or monthly family income.

\section{Conclusions}

The results of this study indicated that the prevalence of $H$. pylori was related to the number of family members and marital status. Our findings also indicated that $H$. pylori infection was not sex-dependent and that alcohol consumption, smoking, and use of non-steroidal antiinflammatory drugs (NSAIDs) did not increase the incidence of $H$. pylori infection. Since the role of $H$. pylori in the physiopathology of gastric ulcer is well understood, in this study, patients with $H$. pylori showed significant differences in endoscopic and pathological findings, especially regarding gastric and duodenal erosions in the presence of complete or incomplete intestinal metaplasia. Considering the important role of $H$. pylori in gastric ulcer and the possible role of other factors in its development, it is recommended to compare the clinical features, endoscopic findings, and pathology reports of patients with gastric ulcer who are positive or negative for $H$. pylori infection. Since in the present study, the relationship between the used drugs and gastric ulcer was not investigated, in future studies, it is recommended to compare this association between different drugs and gastric ulcer.

\section{Abbreviations}

H. pylori: Helicobacter pylori; NSAID: Non-steroidal anti-inflammatory drug; MALT Iymphoma: Gastric marginal zone lymphoma of mucosa-associated Iymphoid tissue; IRIDA: Iron-refractory iron deficiency anemia; BMI: Body mass index; RUT: Rapid urease test; OR: Odd ratio; Cl: Confidence interval.

\section{Acknowledgements}

The authors gratefully acknowledge the all participants in the Gastrointestinal and Liver Disease Research Center and vice-chancellor for research of Guilan University of medical science.

\section{Authors' contributions}

SAH and FM-G and FJ were involved in the study design and data analysis. SK and SY data collection and contributed to data interpretation. MA literature searched. SAH, FM-G and FJ wrote the initial draft of the manuscript, SAH and FJ and MA and FM-G contributed toward its final version. FJ generated of figures. All authors were involved in writing the paper and had final approval of the submitted and published versions.
Funding

None.

Availability of data and materials

The datasets obtained during this study will be available upon request to the corresponding author.

\section{Declarations}

Ethics approval and consent to participate

This study was approved in the Research Department of Guilan University of Medical Sciences with the ethics code of IR.GUMS.REC.1398.145 and with the 1964 Helsinki Declaration and its later amendments or comparable ethical standards. Written Informed consent was obtained from all individual adult participants included in this study. The consent form for illiterate people was read by their first degree relatives and in the absence of the first family, the form was read by one of their trusted people. This manuscript has not been published in whole or in part. All authors have read the manuscript and have agreed that the work is ready for submission and accept responsibility for its contents.

\section{Consent for publication}

Not applicable.

\section{Competing interests}

The authors declare that they have no conflict of interest.

\section{Author details}

${ }^{1}$ Gastrointestinal and Liver Diseases Research Center, Guilan University of Medical Sciences, Rasht, Iran. ${ }^{2}$ Gastrointestinal and Liver Diseases Research Center, Gl Cancer Screening and Prevention Research Center and Caspian Digestive Diseases Research Center, Guilan University of Medical Sciences, Rasht, Iran. ${ }^{3} \mathrm{Gl}$ Cancer Screening and Prevention Research Center, Guilan University of Medical Sciences, Rasht, Iran. ${ }^{4} \mathrm{G}$ Cancer Screening and Prevention Research Center, Gastrointestinal and Liver Diseases Research Center and Caspian Digestive Diseases Research Center, Guilan University of Medical Sciences, Razi Hospital, Sardar-Jangle Ave, Rasht, Iran.

Received: 8 February 2021 Accepted: 20 September 2021

Published online: 27 September 2021

\section{References}

1. Leeja M, Axon A, Brenner H. Epidemiology of Helicobacter pylori infection. Helicobacter. 2016;21:3-7.

2. Venerito M, Vasapolli R, Rokkas T, Delchier JC, Malfertheiner P. Helicobacter pylori, gastric cancer and other gastrointestinal malignancies. Helicobacter. 2017;22:12413.

3. Hudak L, Jaraisy A, Haj S, Muhsen K. An updated systematic review and meta-analysis on the association between Helicobacter pylori infection and iron deficiency anemia. Helicobacter. 2017;22(1):12330.

4. Basta MN. Immune thrombocytopenia is different from thrombotic thrombocytopenic purpura. J Obstet Anaesth Crit Care. 2020;10(1):62.

5. Siddiqua T, Alam MN, Ahmad SM, Haque R, Ahmed T, Allen L, et al. Helicobacter Pylori infection and vitamin B12 deficiency during early pregnancy in an urban slum in Bangladesh (P24-035-19). Curr Dev Nutr. 2019;3(Supplement_1):nzz044. P24-35-19.

6. Suki M, Leibovici Weissman Y, Boltin D, Itskoviz D, Tsadok Perets T, Comaneshter D, et al. Helicobacter pylori infection is positively associated with an increased BMI, irrespective of socioeconomic status and other confounders: a cohort study. Eur J Gastroenterol Hepatol. 2018;30(2):143-8

7. Ghotaslou R, Leylabadlo HE, AsI YM. Prevalence of antibiotic resistance in Helicobacter pylori: a recent literature review. World J Methodol. 2015;5(3):164

8. Bui D, Brown HE, Harris RB, Oren E. Serologic evidence for fecal-oral transmission of Helicobacter pylori. Am J Trop Med Hyg. 2016;94(1):82-8. 
9. Hwang YJ, Kim N, Lee H, Lee J, Choi Y, Yoon H, et al. Reversibility of atrophic gastritis and intestinal metaplasia after Helicobacter pylori eradication-a prospective study for up to 10 years. Aliment Pharmacol Ther. 2018:47(3):380-90.

10. Liu KSH, Wong IOL, Leung WK. Helicobacter pylori associated gastric intestinal metaplasia: treatment and surveillance. World J Gastroenterol. 2016;22(3):1311

11. Bagheri N, Shirzad H, Elahi S, Azadegan-Dehkordi F, Rahimian G, Shafigh $M$, et al. Downregulated regulatory $T$ cell function is associated with increased peptic ulcer in Helicobacter pylori-infection. Microb Pathog. 2017;110:165-75.

12. Schulman AR, Abougergi MS, Thompson CCH. Pylori as a predictor of marginal ulceration: a nationwide analysis. Obesity. 2017;25(3):522-6.

13. Wei Z, Ying L, Wen G, Mengnan Z, Yali Z. Rome III criteria cannot distinguish patients with chronic gastritis from those functional dyspepsia patients. Helicobacter. 2014;19(2):124-8.

14. Klein PD, Opekun A, Smith E, Graham D, Gaillour A, Group GPW. Water source as risk factor for Helicobacter pylori infection in Peruvian children. Lancet. 1991;337(8756):1503-6.

15. Garza-González E, Perez-Perez Gl, Maldonado-Garza HJ, Bosques-Padilla FJ. A review of Helicobacter pylori diagnosis, treatment, and methods to detect eradication. World J Gastroenterol WJG. 2014;20(6):1438.

16. Sakaki N, Kozawa H. Intestinal metaplasia and Helicobacter pylori infection, their relationship and effects of eradication therapy. Nihon Rinsho. 2001;59:361-6.

17. Mansour-Ghanaei F, Joukar F, Soati F, Mansour-Ghanaei A, Atrkar-Roushan Z. Outcome of intestinal metaplasia in gastric biopsy of patients with dyspepsia in Guilan Province, North Iran. Asian Pac J Cancer Prev. 2013;14(6):3549-54.

18. Graham DY, Malaty HM, Evans DG, Evans DJ Jr, Klein PD, Adam E. Epidemiology of Helicobacter pylori in an asymptomatic population in the United States: effect of age, race, and socioeconomic status. Gastroenterology. 1991;100(6):1495-501.

19. Rowland M, Daly L, Vaughan M, Higgins A, Bourke B, Drumm B. Age-specific incidence of Helicobacter pylori. Gastroenterology. 2006;130(1):65-72.

20. Tindberg Y, Blennow M, Bengtsson C, Granström M, Granath F, Nyrén O. Helicobacter pylori infection in Swedish school children: lack of evidence of child-to-child transmission outside the family. Gastroenterology. 2001;121(2):310-6.

21. Blaser MJ, Chyou P, Nomura A. Age at establishment of Helicobacter pylori infection and gastric carcinoma, gastric ulcer, and duodenal ulcer risk. Cancer Res. 1995;55(3):562-5.

22. Toyoshima O, Yamaji Y, Yoshida S, Matsumoto S, Yamashita H, Kanazawa T, et al. Endoscopic gastric atrophy is strongly associated with gastric cancer development after Helicobacter pylori eradication. Surg Endosc. 2017;31(5):2140-8

23. Zamani M, Ebrahimtabar F, Zamani V, Miller WH, Alizadeh-Navaei R, ShokriShirvani J, Derakhshan MH. Systematic review with meta-analysis: the worldwide prevalence of Helicobacter pylori infection. Aliment Pharm Ther. 2018:47:868-76

24. Zhu Y, Zhou X, Wu J, Su J, Zhang G. Risk factors and prevalence of Helicobacter pylori infection in persistent high incidence area of gastric carcinoma in Yangzhong City. Gastroenterol Res Pract. 2014;2014:481365.

25. Shinchi K, Ishii H, Imanishi K, Kono S. Relationship of cigarette smoking, alcohol use, and dietary habits with Helicobacter priori infection in Japanese men. Scand J Gastroenterol. 1997;32(7):651-5.

26. Battaglia G, Di Mario F, Pasini M, Donisi PM, Dotto P, Benvenuti ME, et al. Helicobacter pylori infection, cigarette smoking and alcohol consumption. A histological and clinical study on 286 subjects. Ital J Gastroenterol. 1993;25(8):419-24

27. Zhong C, Li K-N, Bi J-W, Wang B-C. Sodium intake, salt taste and gastric cancer risk according to Helicobacter pylori infection, smoking, histological type and tumor site in China. Asian Pac J Cancer Prev. 2012;13(6):2481-4.

28. Choi IJ, Kim CG, Lee JY, Kim Y-I, Kook M-C, Park B, et al. Family history of gastric cancer and Helicobacter pylori treatment. N Engl I Med. 2020;382(5):427-36.

29. Nouraie M, Latifi Navid S, Rezvan H, Radmard AR, Maghsudlu M, Zaer-Rezaii $\mathrm{H}$, et al. Childhood hygienic practice and family education status determine the prevalence of Helicobacter pylori infection in Iran. Helicobacter. 2009;14(1):40-6.
30. The EUROGAST Study Group. Epidemiology of, and risk factors for, Helicobacter pylori infection among 3194 asymptomatic subjects in 17 populations. Gut. 1993;34:1672-6.

31. Chang WK, Kim HY, Kim DJ, Lee J, Park CK, Yoo JY, et al. Association between Helicobacter pylori infection and the risk of gastric cancer in the Korean population: prospective case-controlled study. J Gastroenterol. 2001;36:816-22.

32. Shi R, Shunfu Xu, Zhang H, Ding Y, Sun G, et al. Prevalence and risk factors for Helicobacter pylori infection in Chinese populations. Helicobacter. 2008;13(2):157-65.

33. Moreira ED Jr, Santos RS, Nassri VB, Reis AT, Guerra AL, Alcântara APG, et al. Risk factors for Helicobacter pylori infection in children: is education a main determinant? Epidemiol Infect. 2004;132:327-35.

34. Zhu B-Y, Tang Z, She J, Liang X-Y, Dong L-K, Zhang M. Epidemiological investigation of Helicobacter pylori infection in elderly people in Beijing Hong-Ming. World J Clin Cases. 2020;8(11):2173-80.

35. Zhu HM, Li BY, Tang Z, She J, Liang XY, Dong LK, Zhang M. Epidemiological investigation of Helicobacter pylori infection in elderly people in Beijing. World J Clin Cases. 2020;8(11):2173-80.

36. Zamani M, Ebrahimtabar F, Zamani V, Miller WH, Alizadeh-Navaei R, ShokriShirvani J, Derakhshan MH. Potential risk factors and prevalence of Helicobacter pylori infection among adult patients with dyspepsia symptoms in Cameroon. Pharmacol Ther. 2018:47:868-76.

37. Moayyedi P, Axon AT, Feltbower R, Duffett S, Crocombe W, Braunholtz D, Richards IDG, Dowell AC, Forman D. Relation of adult lifestyle and socioeconomic factors to the prevalence of Helicobacter pylori infection. Int J Epidemiol. 2002;31(3):624-31.

38. Lehmann FS, Renner EL, Meyer-Wyss B, Wilder-Smith CH, Mazzucchelli L, Ruchti $C$, et al. Helicobacter pylori and gastric erosions. Results of a prevalence study in asymptomatic volunteers. Digestion. 2000;62(2-3):82-6.

39. Zhang C, Yamada N, Wu Y-L, Wen M, Matsuhisa T, Matsukura N. Helicobacter pylori infection, glandular atrophy and intestinal metaplasia in superficial gastritis, gastric erosion, erosive gastritis, gastric ulcer and early gastric cancer. World J Gastroenterol. 2005;11(6):791-6.

40. Kuipers $\mathrm{E}$, Thijs J, Festen $\mathrm{H}$. The prevalence of Helicobacter pylori in peptic ulcer disease. Aliment Pharmacol Ther. 1995;9:59-69.

41. Chu K-M, Kwok K-F, Law S, Wong K-H. Patients with Helicobacter pylori positive and negative duodenal ulcers have distinct clinical characteristics. World J Gastroenterol WJG. 2005;1 1(23):3518.

42. Meucci G, Di Battista R, Abbiati C, Benassi R, Bierti L, Bortoli A, et al. Prevalence and risk factors of Helicobacter pylori-negative peptic ulcer: a multicenter study. J Clin Gastroenterol. 2000;31(1):42-7.

43. Tovey Fl, Hobsley M. Is Helicobacter pylori the primary cause of duodenal ulceration? J Gastroenterol Hepatol. 1999;14(11):1053-6.

44. Bytzer P, Teglbjaerg PS. Helicobacter pylori-negative duodenal ulcers: prevalence, clinical characteristics, and prognosis-results from a randomized trial with 2-year follow-up. Am J Gastroenterol. 2001;96(5):1409-16.

45. Wang C-A, Liu Y-C, Du S-Y, Lin C-W, Fu H-W. Helicobacter pylori neutrophilactivating protein promotes myeloperoxidase release from human neutrophils. Biochem Biophys Res Commun. 2008;377(1):52-6.

46. Fontham ET, Ruiz B, Perez A, Hunter F, Correa P. Determinants of Helicobacter pylori infection and chronic gastritis. Am J Gastroenterol. 1995;90(7):1094-101.

47. Silva S, Filipe M, Pinho A. Variants of intestinal metaplasia in the evolution of chronic atrophic gastritis and gastric ulcer. A follow up study. Gut. 1990;31(10):1097-104.

48. Nordenstedt H, Graham DY, Kramer JR, Rugge M, Verstovsek G, Fitzgerald S, et al. Helicobacter pylori-negative gastritis: prevalence and risk factors. Am J Gastroenterol. 2013;108(1):65-71.

49. Crafa P, Russo M, Miraglia C, Barchi A, Moccia F, Nouvenne A, et al. From sidney to OLGA: an overview of atrophic gastritis. Acta Biomed. 2018;89(8S):93-9.

50. Muhsen K, Sinnreich R, Beer-Davidson G, Nassar H, Cohen D, Kark JD. Seroprevalence of Helicobacter pylori CagA immunoglobulin G antibody, serum pepsinogens and haemoglobin levels in adults. Sci Rep. 2018;8:17616.

\section{Publisher's Note}

Springer Nature remains neutral with regard to jurisdictional claims in published maps and institutional affiliations. 